\title{
DESIGN OF QUICK CONNECT-DisCONNECT HYDRAULIC COUPLING
}

\author{
Rohit George Sebastian ${ }^{1}$ and Satheesh Kumar S. ${ }^{2}$ \\ ${ }^{1}$ Final year B.Tech student, Department of Mechanical Engineering, Government \\ Engineering College Barton Hill, Thiruvanthapuram, Kerala, India \\ rohit.sebastian@gmail.com \\ ${ }^{1}$ Assistant Prodessor, Department of Mechanical Engineering, Government Engineering \\ College Barton Hill, Thiruvanthapuram, Kerala, India \\ satheeshgecb@gmail.com
}

\begin{abstract}
Quick Connect-Disconnect Couplings (QCDCs) provide a means of rapidly disconnecting a fluid line without loss of hydraulic fluid or entrance of air into the system. They are most commonly used for hydraulic systems in aerospace applications like space stations, launch vehicles, etc. Information regarding the design of QCDCs is not available in open literature. This paper details the preliminary design and optimization of QCDCs for indigenization of the technology, and the general configuration arrived at. A QCDC consists of two halves - a male half and a female half. The sealing action is achieved by using poppet valve in the male half and a moveable sleeve in the female half. $O$-rings are used to ensure that the design is leak-proof. Changes in pressure and velocity of the fluid flowing through the QCDC have been kept to a minimum by ensuring gradual changes in cross-section wherever possible.
\end{abstract}

\section{KEYWORDS}

QCDC, quick connect, quick disconnect, hydraulic coupling, fluid coupling

\section{INTRODUCTION}

Quick Connect-Disconnect Couplings (QCDCs) provide a fast, convenient way to repeatedly connect and disconnect fluid lines without the loss of hydraulic fluid or entrance of air into the system. All QCDCs have two parts: a plug and a socket. The plug is the male half and the socket is the female half. When connected properly, these parts seal and lock the joint effectively to contain internal pressures and resist any tensile forces that tend to pull the joint apart. The parts are easily disconnected without tools by disengaging a locking mechanism and separating the parts. Each half contains a valve, which is held open when the coupling is connected. This action allows fluid to flow in either direction through the coupling. When the coupling is disconnected, a spring in each half closes the valve, preventing the loss of fluid and entrance of air. The union nut has a quick-lead thread that permits connecting or disconnecting the coupling by turning the nut.

\section{DESIGN CONFIGURATION}

The male half of the QCDC consists of a poppet valve, a compression spring, a guide for gradually altering the direction of fluid flow, and the main coupling body. The guide ensures that the changes in cross-section are gradual. For this, the guide offers a tapered flow path to the hydraulic fluid. The walls of the coupling body and the tail of the poppet valve are also tapered to 
provide a tapered flow path between changes in diameter. A spring cover which is welded to the back face of the poppet valve also aids to give a gradual and uniform change in diameter. The spring cover also serves the additional purpose of avoiding the formation of eddies (which would have contributed to pressure losses) at the back of the poppet valve. The guide also ensures that no component comes directly in the path of the fluid flow (which would have contributed to pressure losses). The guide also supports the compression spring and also helps to prevent it from buckling. The compression spring is held between a projection on the guide and the back face of the poppet valve. The poppet valve remains suspended in the hydraulic fluid. The valve surrounds the tail of the poppet valve and ensures that the poppet valve does not deviate too much from its axis. The tail of the poppet valve is provided with several circular grooves along its length. Fluid under pressure enters these grooves and provides a cushioning effect between the poppet valve and the valve guide, helping to prevent the tail of the poppet valve from coming in contact with the valve guide. In order to assemble the QCDC, the coupling body is made as 2 parts and then welded together after fixing all the internal components in their respective places. A triple start thread is provided on the outer surface of the coupling body to facilitate mating of the male and female halves of the QCDC. A valve seat is also incorporated into the coupling body. An O-ring is provided close to the valve seat to prevent leakage of the QCDC.

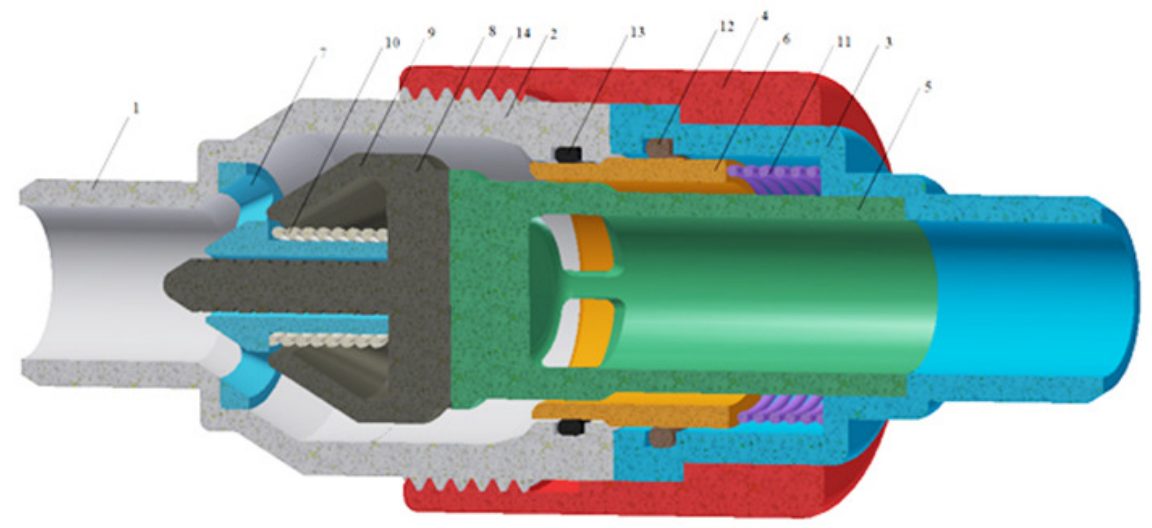

The different parts of the QCDC: 1, 2- Male Coupling Body, 3, 4-Female Coupling Body, 5 - Female

Flow Cavity, 6 - Sleeve, 7 - Male Guide, 8 - Poppet Valve, 9 - Spring Cover, 10 - Male Compression

Spring, 11 -Female Compression Spring, 12 -Female O-ring, 13 - Male O-ring, 14 -Triple-start Thread

Figure 1. Half-sectional view of QCDC in coupled position showing the different parts

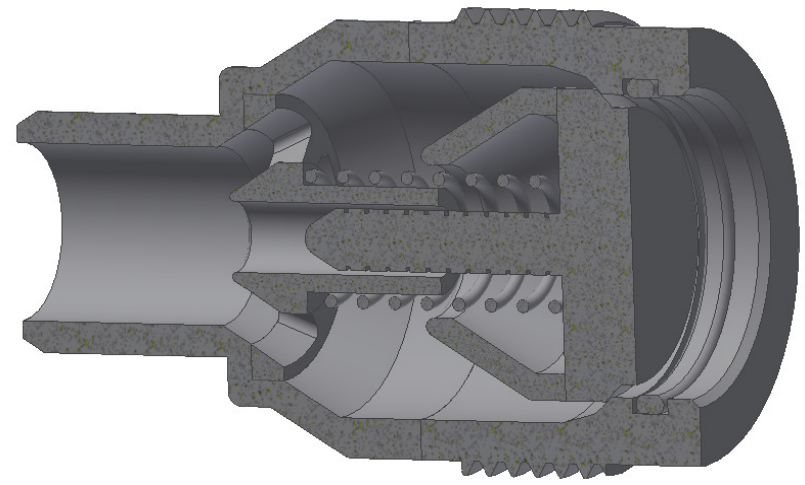

Figure 2. Half-sectional view of male half in uncoupled position

The female half consists of a flow cavity, a sleeve, a compression spring, and the main coupling body. As in the male half, the flow cavity ensures that the changes in cross-section are gradual. 
For this, the flow cavity offers a tapered flow path to the hydraulic fluid. The sleeve lies between the flow cavity and the coupling body. The compression spring is held between the inner surface of the coupling body and the back face of the sleeve. The sleeve remains suspended in the hydraulic fluid. An O-ring is provided in the coupling body above the narrow end of the sleeve to prevent leakage of the QCDC. To facilitate easy machining of the gland for the O-ring, the coupling body is made as 2 parts and threaded together. A triple start thread, matching the one on the male half is provided on the coupling body to facilitate mating of the male and female halves of the QCDC.

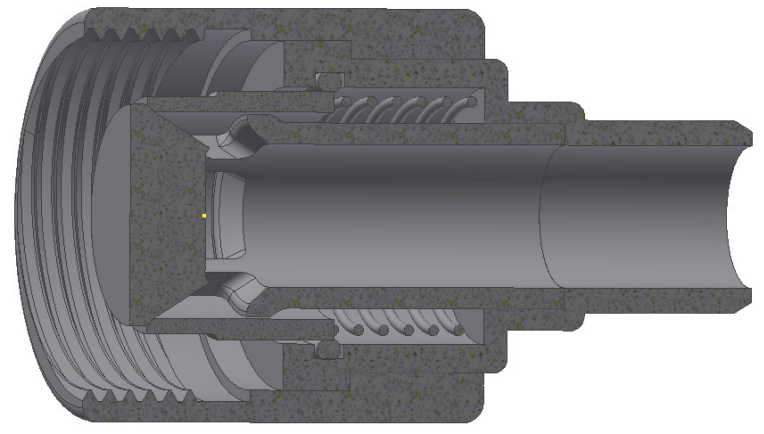

Figure 3. Half-sectional view of female half in uncoupled position

In the closed or uncoupled position, the poppet valve in the male half pushes against a valve seat preventing leakage of hydraulic fluid and any entry of air into the system. The compression spring keeps the poppet valve firmly seated against the valve seat in the uncoupled or closed position. In the female half of the QCDC, a sleeve is responsible for sealing action in the closed or uncoupled condition. The compression spring pushes the sleeve against a valve seat.

In the coupled position, the flat face of the female half pushes against the head of the poppet valve, pushing it backwards. At the same time, the valve seat in the male half pushes the sleeve in the female half backwards, opening a path for the hydraulic fluid to flow. The fluid flows over the circular face of the female half and the poppet valve in the male half in an annular flow path formed by the mating of the two coupling halves.

\section{Design PARAMeters}

1. Operating Static Pressure - 20.7MPa

2. Burst Pressure $-82.8 \mathrm{MPa}$

3. Rated Flow $-23 \mathrm{~L} / \mathrm{min}$

4. Inlet Flow Velocity $-1.5 \mathrm{~m} / \mathrm{s}$

5. Specific Gravity of Fluid -0.85

6. Kinematic Viscosity of Fluid $-14.2 \mathrm{cSt}$

\section{Material Selection}

The coupling should be made of a material with high yield stress (to minimize weight) and with high corrosion resistance to prevent corrosion due to the fluid flowing inside. 15-5 PH stainless steel (with yield stress of $958 \mathrm{MPa}$ [1] Rockwell $\mathrm{C}$ hardness 40[2]) has been chosen to make the coupling body, which includes the stoppers and guides for the poppet valve. 15-5 PH steel has high strength and hardness along with excellent corrosion resistance, making it ideally suited for this application. The valve seat should be able to withstand shearing forces due to the force 
imparted by the poppet valve when it is seated (these forces are due to fluid pressure acting on the back of the poppet head and due to the force from the spring), despite having a small area of contact with the inner wall of the coupling. Hence, 15-5 PH steel is suitable for the valve seats as well.

For proper seating of the poppet valve, the valve seat must be softer than the valve, so that it can deform slightly (a slight deformation of the valve seat is required for the proper seating of the valve). Also the same time, the sleeve should bear the pressure of the hydraulic fluid in the uncoupled position. For this, a material with hardness greater than that of $15-5 \mathrm{PH}$ stainless steel while still having high yield strength is needed. AISI 440C Martensitic stainless steel hardened by quenching in oil at $1030 \mathrm{oC}$ and tempered at $150 \mathrm{oC}$ (with yield stress of $1930 \mathrm{MPa}$ and Rockwell $\mathrm{C}$ hardness 60[3]) has been chosen for the poppet valve and the sleeve.

The most suitable material for springs are those which can store up the maximum amount of work or energy in a given weight or volume of spring material, without permanent deformation. These steels should have a high elastic limit as well as high deflection value. Spring steel should also possess maximum strength against fatigue effects and shocks. For the compression spring, we have chosen music wire.[4]

The compound for the O-ring is selected considering several factors such as fluid compatibility, the effect of various operating environments and conditions, etc. We are designing a QCDC for use with a petroleum-based hydraulic fluid. Considering compatibility with the hydraulic fluid and the required operating conditions, Acrylonitrile-Butadiene (NBR) is the best suited compound for the O-ring.[5]

Table 1. Parts and the materials chosen

\begin{tabular}{|c|l|l|}
\hline Sl. No. & \multicolumn{1}{|c|}{ Part } & \multicolumn{1}{c|}{ Material Chosen } \\
\hline 1 & Male Coupling Body 1 & $15-5$ PH stainless steel \\
\hline 2 & Male Coupling Body 2 & $15-5$ PH stainless steel \\
\hline 3 & Female Coupling Body 1 & $15-5$ PH stainless steel \\
\hline 4 & Female Coupling Body 2 & $15-5$ PH stainless steel \\
\hline 5 & Female Flow Cavity & $15-5$ PH stainless steel \\
\hline 6 & Male Guide & $15-5$ PH stainless steel \\
\hline 7 & Sleeve & $\begin{array}{l}\text { AISI 440C Martensitic stainless } \\
\text { steel }\end{array}$ \\
\hline 8 & Poppet Valve & $\begin{array}{l}\text { AISI 440C Martensitic stainless } \\
\text { steel }\end{array}$ \\
\hline 9 & Spring Cover & $\begin{array}{l}\text { AISI 440C Martensitic stainless } \\
\text { steel }\end{array}$ \\
\hline 10 & $\begin{array}{l}\text { Compression spring for male } \\
\text { half }\end{array}$ & Music wire \\
\hline 11 & $\begin{array}{l}\text { Compression spring for female } \\
\text { half }\end{array}$ & Music wire \\
\hline 12 & O-ring for male half & Acrylonitrile-Butadiene \\
\hline 13 & O-ring for female half & Acrylonitrile-Butadiene \\
\hline
\end{tabular}




\section{DESIGN OF INDIVIDUAL COMPONENTS}

The body of the QCDC can be considered as a pressure vessel. For ease of machining and assembly, both male and female halves of the coupling have been designed as two separate parts. The two parts of the male half are welded together along the circumference of the meeting edges, by butt welding using either TIG welding or electron beam welding. The two parts of the female coupling are threaded together, and for this, threads are cut on the parts as shown in the figure. The thickness of the body for different diameters were found based on strength using Lame's equation [6], with a factor of safety of 2 and a proof pressure of $82.8 \mathrm{MPa}$.

According to Lame's equation,

$$
\mathrm{t}=\mathrm{r}_{\mathrm{i}}\left[\sqrt{\frac{\pi}{\tau-\mathrm{p}}}-1\right]
$$

where, $t$ is the thickness, $r_{i}$ is the internal radius, $p$ is the internal pressure and $\tau$ is the design value of shear stress.

The thicknesses of some internal cylindrical components such as the flow cavity of the female half and the sleeve were also found in this way with the same factor of safety, but with a proof pressure of $20.7 \mathrm{MPa}$ for the sleeve. The thickness obtained is rounded off to a convenient value, and in some cases, increased to account for additional factors such as cutting of threads, to account for the reduced strength at welded joints, etc.

Since the parts joined by threads are of the same material, shear stress occurs at the pitch line. The threads designed have a very high margin of safety. The springs have also been designed to withstand the shear stress caused due to the curvature of the wire and axial loading, with a factor of safety of 1.5 .

\section{ASSEMBLY}

The coupling body of the male half of the QCDC is made as 2 pieces. The male guide is threaded to the piece of the male coupling body which has the fluid outlet. The compression spring for the poppet valve is inserted over the cylindrical portion of the male guide, and the poppet valve is inserted such that the cylindrical portion of the male guide covers the stem of the poppet valve and its head rests on the compression spring. The O-ring is inserted into the other piece of the male half coupling body in the groove provided. The poppet valve should be held back before the two pieces of the male half coupling are butt welded together by either TIG welding or electron beam welding.

The coupling body of the female half is also made as 2 pieces. The compression spring for the sleeve is inserted into the piece having the hydraulic fluid inlet in the cavity provided for the sleeve and the compression spring. The sleeve is also inserted into the same cavity so that the broader flat face rests on the compression spring. The sleeve should be held back before the female flow cavity is threaded into place. The two pieces of the coupling body of the female half are now threaded together.

Since the above mentioned threaded connections (in both the male and female halves) are permanent, they are backed up by industrial grade adhesives in the thread cavity. 
International Journal of Recent advances in Mechanical Engineering (IJMECH) Vol.3, No.3, August 2014

\section{ENGINEERING DRAWINGS}
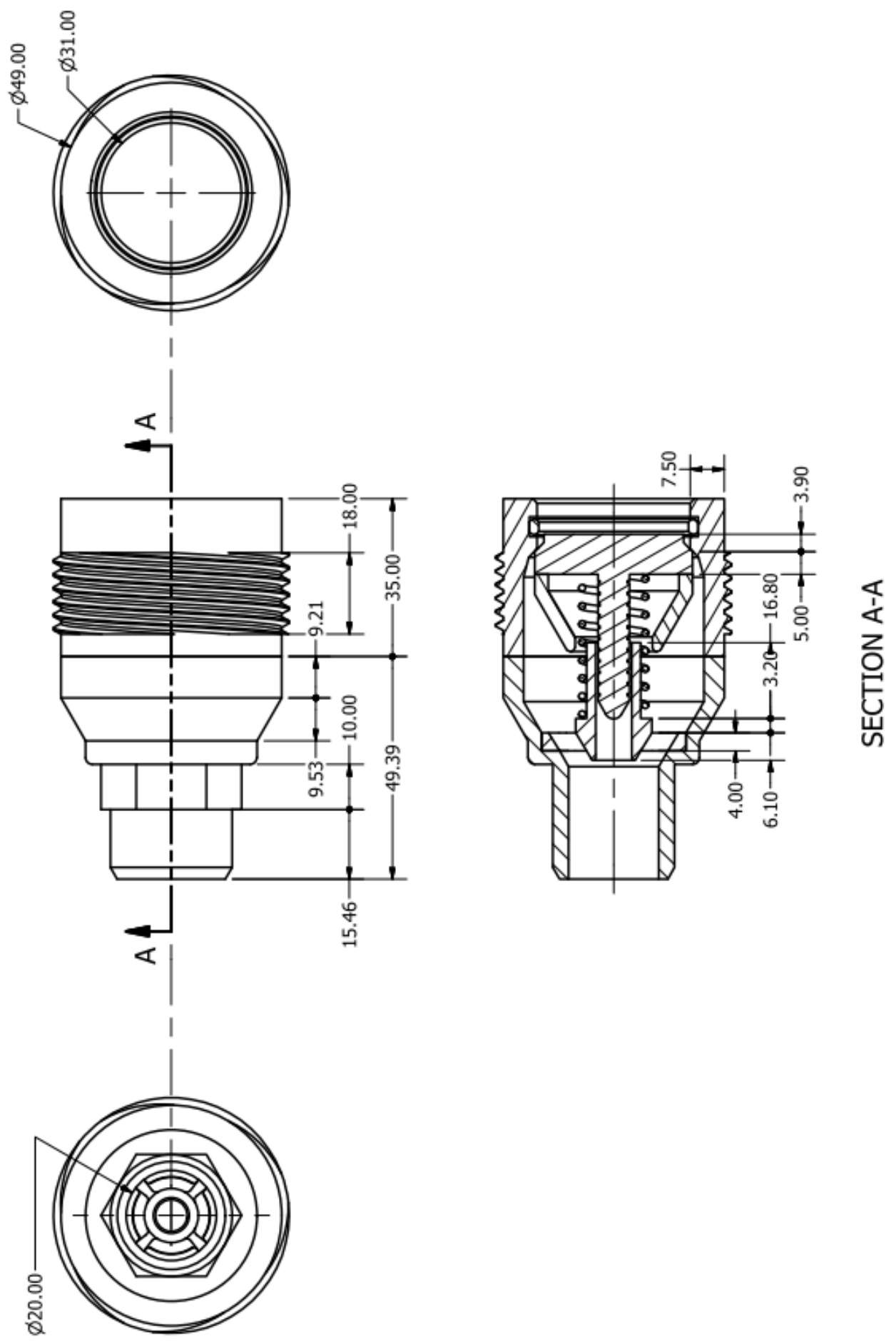

Figure 4. 2D drawing of male half in uncoupled position 
International Journal of Recent advances in Mechanical Engineering (IJMECH) Vol.3, No.3, August 2014
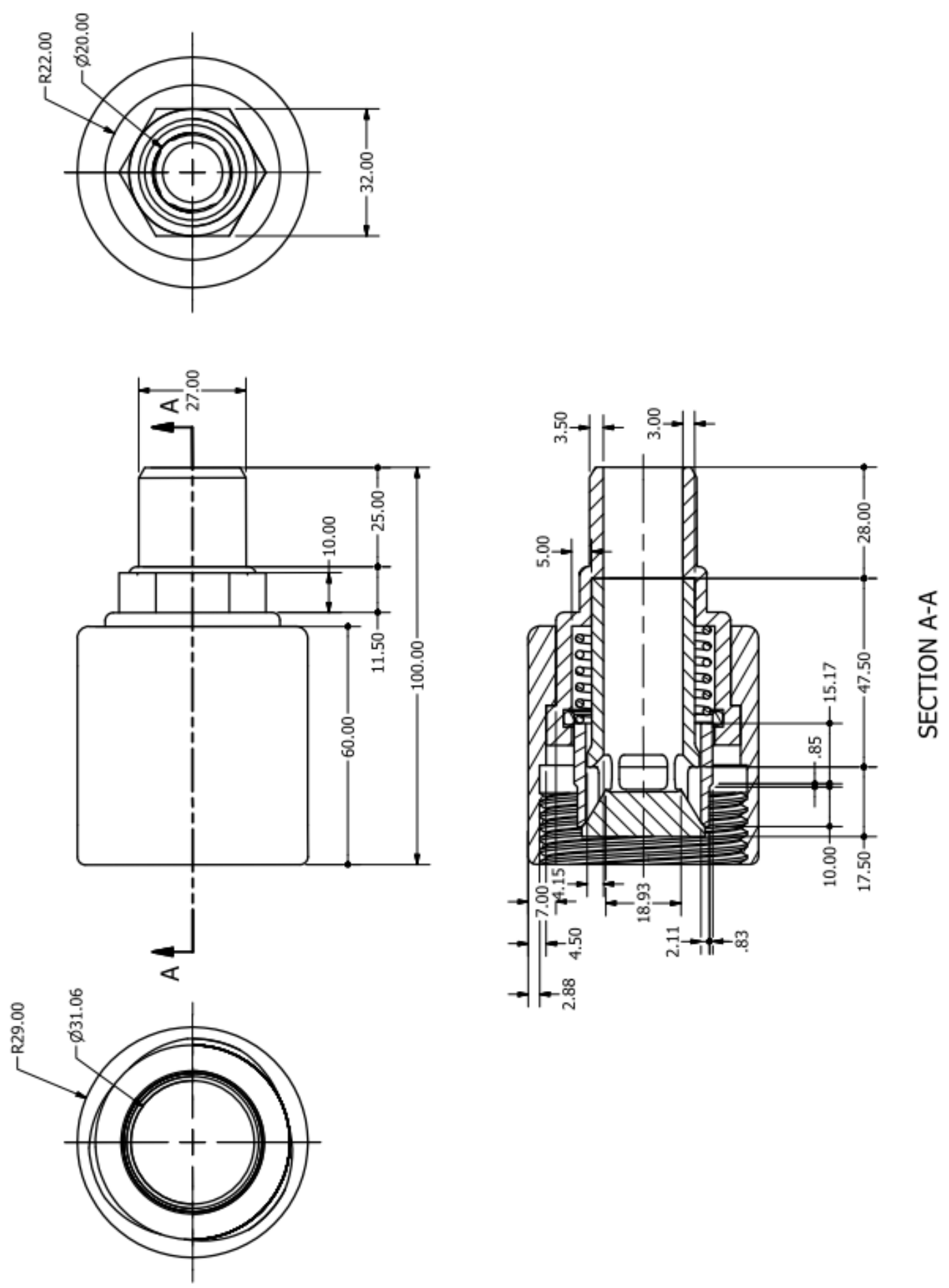

Figure 5. 2D drawing of female half in uncoupled position 
International Journal of Recent advances in Mechanical Engineering (IJMECH) Vol.3, No.3, August 2014
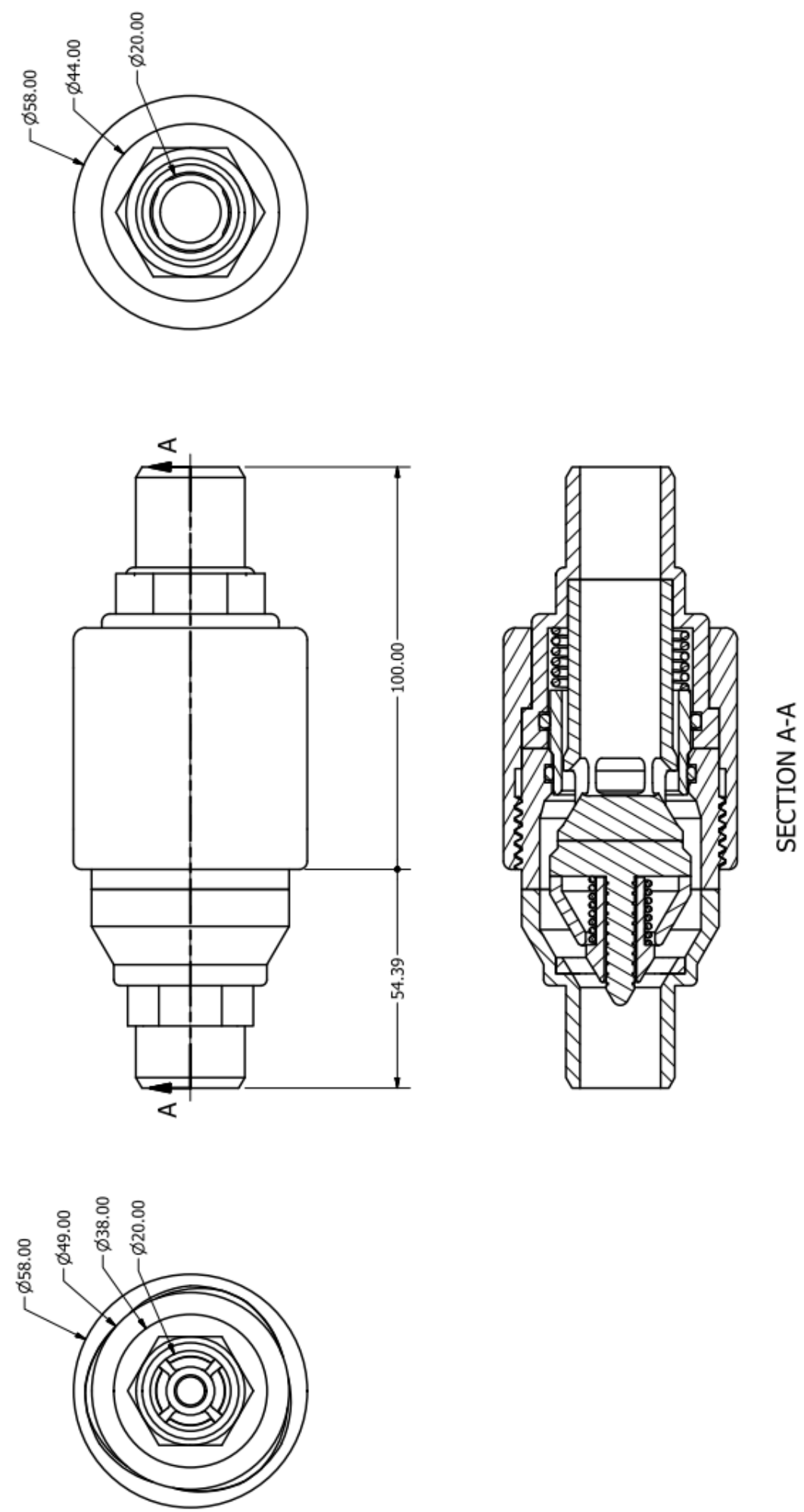

Figure 6. 2D drawing of QCDC in coupled position 


\section{CFD AnAlysis AND RESUlts}

CFD analysis of the 3D model of the QCDC was done using Comsol Multiphysics for fluid flow from the female half to the male half for the selected parameters, with inlet pressure of $207 \mathrm{bar}$ and exit flow rate of $24 \mathrm{lpm}$ as the boundary conditions. FEA of the model has resulted in the following results:

1. The maximum fluid velocity in the coupling has been found to be $2.5063 \mathrm{~ms}-1$. Since the average inlet velocity is $1.5 \mathrm{~ms}-1$, there is not much change in velocity over the QCDC.

2. The plot of Reynolds number shows that fluid flow is found to be laminar throughout the QCDC.

3. The exit pressure has been found to be 206.95437 bar, which means the pressure drop across the QCDC is 0.04563 bar (less than $0.25 \%$ of the inlet pressure).

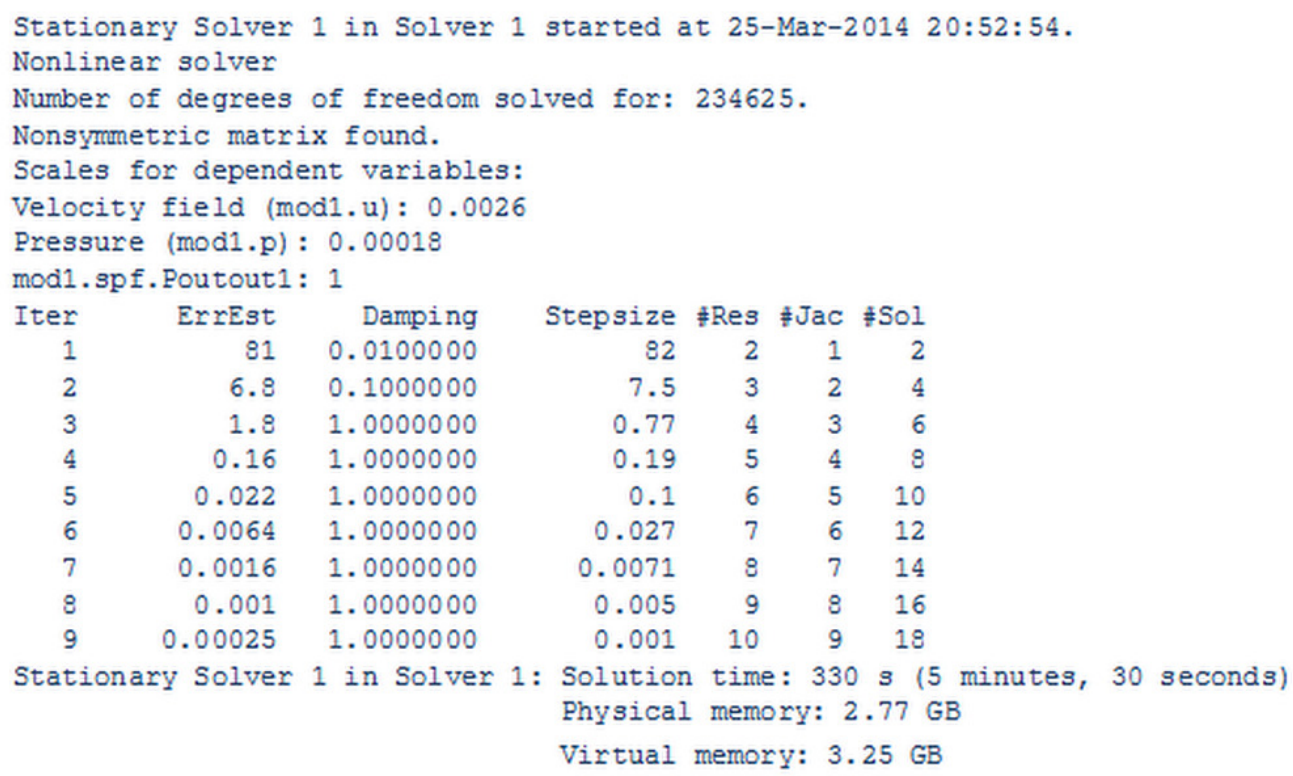

Figure 7. Solver Log

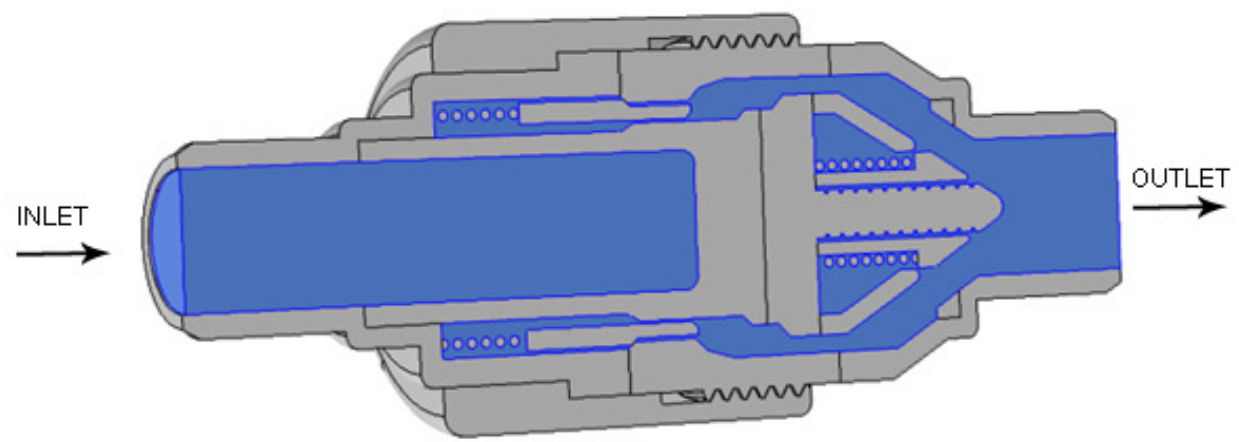

Figure 10: Direction of fluid flow 
International Journal of Recent advances in Mechanical Engineering (IJMECH) Vol.3, No.3, August 2014

Slice: Velocity magnitude $(\mathrm{m} / \mathrm{s})$
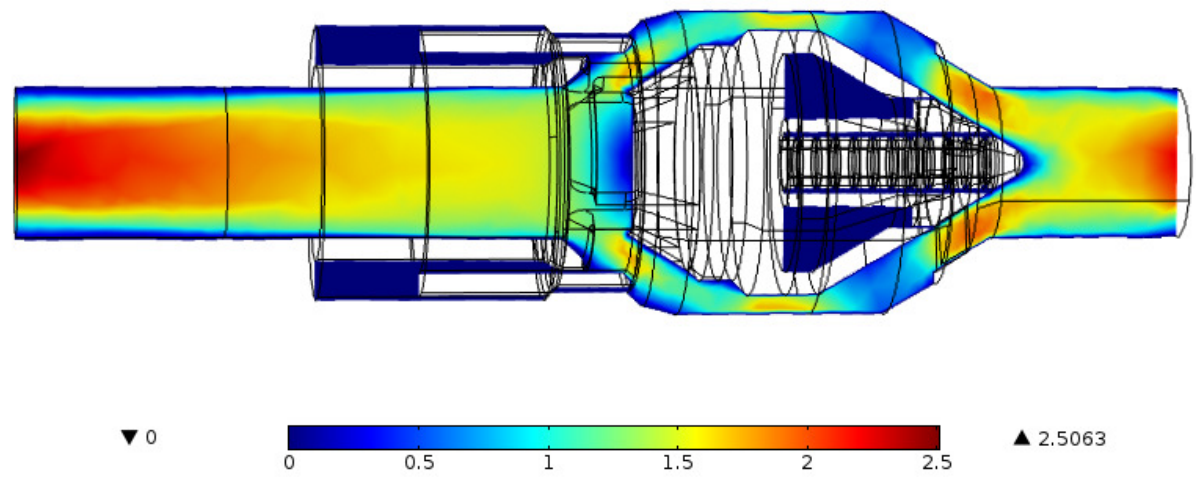

Figure 4.5 Velocity distribution

Slice: Cell Reynolds number (1)

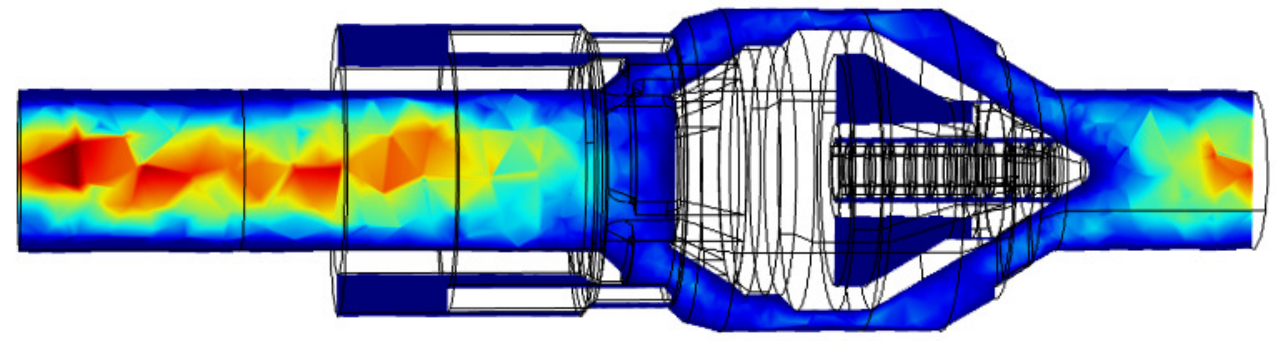

$\boldsymbol{\nabla} 0$

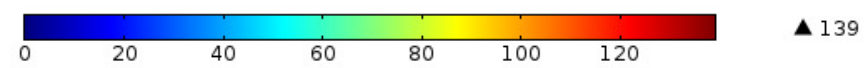

Figure 4.7 Plot of Reynolds number Slice: Pressure (bar)

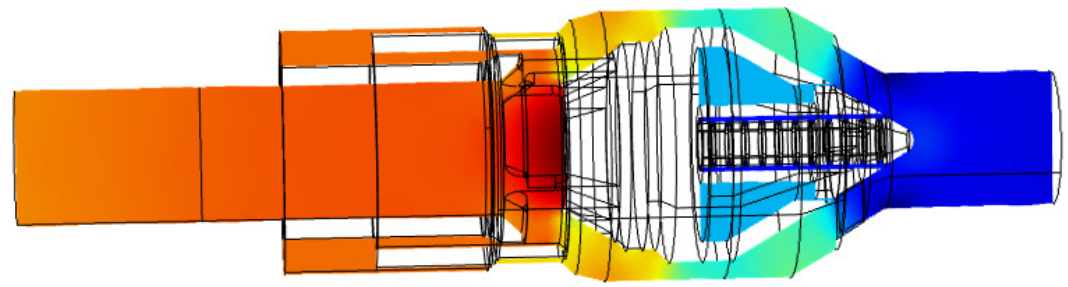

$\mathbf{\nabla} 206.95$

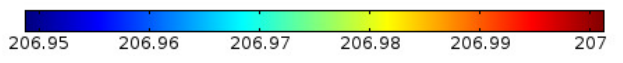

A 207

Figure 4.9 Pressure distribution 
Arrow Volume: Velocity field

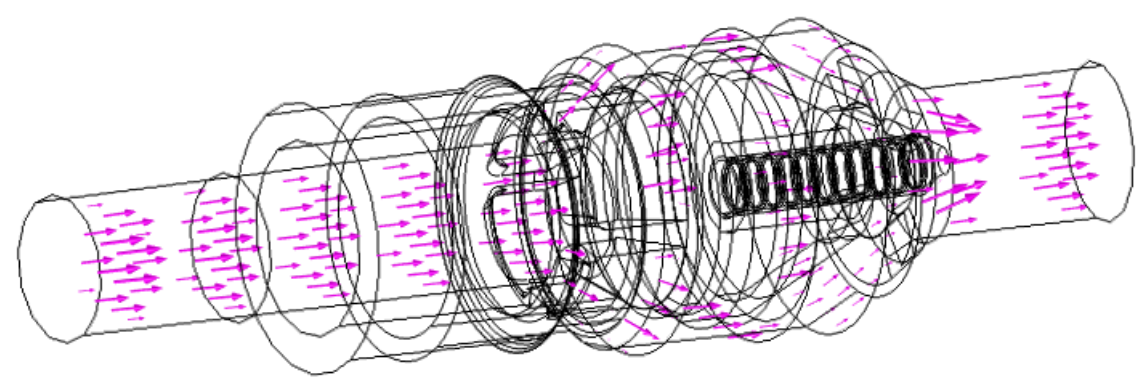

Figure 4.8 Direction of fluid flow

\section{Applications}

1. In assembly workstations, to rapidly switch from one tool to another.

2. On hydraulic test stands.

3. In space stations, where fluid lines need to be connected or disconnected from life support systems or similar critical machines for maintenance purposes without shutting down the system.

\section{Conclusion}

The design work undertaken has resulted in the following achievements:

1. General design of the QCDC was completed.

2. The design was optimized for the selected parameters taking into consideration several factors such as compactness of the system, weight, corrosion resistance and ability to withstand the required high operating pressures.

3. The flow characteristics of hydraulic fluid through the QCDC were determined using CFD analysis and found to be well within acceptable limits. The fluid flow is laminar throughout the length of the QCDC with no formation of eddies. The pressure drop over the QCDC was found to be less than $0.25 \%$ of the inlet pressure for the selected flow parameters.

4. The design work and associated data generated in this study will serve as a reference for future applications.

\section{ACKNOWLEDGEMENTS}

The authors would like to thank Mr. V. Masilamani (Head, DDH, QIDM, AVN, VSSC) and Mr. Sankar Narayanan (ACSS, EHAD, CASG, VSSC) for their guidance, suggestions, positive criticism and valuable insights. The authors would also like to thank Dr. R. Sathikumar (Principal) and Dr. Bindu Kumar K. (H.O.D., Mechanical Engineering) for the facilities provided by the Government Engineering College, Barton Hill, Trivandrum. 


\section{REFERENCES}

[1] AISI Type S15500 (15Cr-5Ni) Precipitation Hardening Stainless Steel tested at $205^{\circ} \mathrm{C}\left(400^{\circ} \mathrm{F}\right)$, condition H1025.

Available: http://asm.matweb.com/search/SpecificMaterial.asp?bassnum=MQM15AM

[2] Stainless Steel - Precipitation Hardening - $15 / 5 \quad$ PH. Available: http://www.aalco.co.uk/datasheets/Stainless-Steel_15 5-PH_310.ashx

[3] 440C Martensitic Stainless Steel Bar. Available: http://www.interlloy.com.au/our-products/stainlesssteel/440c-martensitic-stainless-steel-bar/

[4] Materials - Music Wire. Available: http://www.springsandthings.com/music-wire.html

[5] Parker O-ring Handbook. Available: http://www.parker.com/literature/ORD\%205700\%20Parker_ORing_Handbook.pdf

[6] John F. Harvey (1985) Theory and Design of Pressure Vessels, Van Nostrand Reinhold Company

\section{Authors}

Rohit George Sebastian is a final year B.Tech student (Mechanical Engineering) studying at Government Engineering College, Barton Hill, Thiruvananthapuram.

Satheesh Kumar S, studied B.Tech (Mechanical Engineering) in College

of

Engineering, Thiruvananthapuram and M.Tech (Machine Design) in IIT Madras. Joined Kerala Government Service as Assistant Engineer in 2000 and is currently working as Assistant Professor in the Department of Mechanical Engineering, Government Engineering College, Barton Hill, Thiruvananthapuram, Kerala.
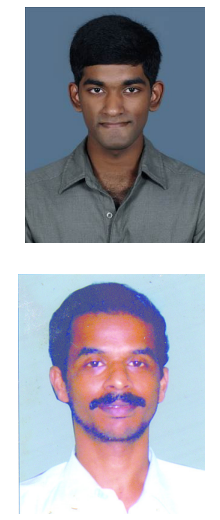